\title{
Natural language mediation: A source of interference with extra-experimental interference $^{1}$
}

\author{
WILLIAM E. MONTAGUE AND ALEXANDER J. WEARING ${ }^{2}$ \\ UNIVERSITY OF ILLINOIS, URBANA
}

Extra-experimental sources of interference have been postulated to explain the forgetting which takes place when Ss who are naive to verbal learning experiments learn a list and later recall it. However, in contradiction to the predictions of interference theory, several experiments have failed to show any effects of extra-experimental interference. The present experiment replicates Ekstrand \& Underwood (1965) and shows that these findings may be due to $S$ 's use of natural language mediators (NLMs) which make it inappropriate to manipulate extra-experimental interference using letter associations.

Extra-experimental sources of interference have been postulated to explain the forgetting which takes place when Ss who are naive to verbal learning experiments learn a list and then recall it $24 \mathrm{~h}$ later. Underwood (1957) has estimated that the loss will be in the neighborhood of $15-25 \%$. Since no obvious sources of interference exist to account for this loss, Underwood \& Postman (1960) assume that the interference must arise from associations which were learned prior to the experiment. This proactive inhibition (PI) hypothesis follows logically from experimental results which show PI where the learning and recall of one list is degraded by the prior learning of another list (Adams, 1967).

However, the findings of several experiments have failed to support the extra-experimental interference hypothesis (Postman, 1961, 1962; Underwood, 1964; Underwood \& Ekstrand, 1966, 1967; Underwood \& Keppel, 1963; Underwood \& Postman, 1960). Underwood \& Ekstrand (1966) conclude that "...the source of interference cannot be linguistic habits of long standing, or, if they are, our methods of "bringing them into the laboratory' are quite inadequate." (p. 548).

The reason for these findings may be due to the fact that in paired associate (PA) learning Ss try to "hook up"' (Underwood \& Schultz, 1960, p. 284) pairs of items by various mnemonic or associative devices which serve to facilitate learning and protect the pairs from interference. In a number of experiments it has been found that Ss use natural language mediators (NLMs) to facilitate the learning and recalling of PA items (Kiess \& Montague, 1965; Montague, Adams, \& Kiess, 1966; Montague \& Wearing, 1967; Wearing \& Montague, 1967). It is possible that NLMs may be formed between pairs, and that these would then override the effects of extra-experimental sources of interference as manipulated by Underwood, Postman, and their associates.

The present experiment examines the role of NLMs in learning lists of letter pairs of different letter association probabilities.

\section{Subjects}

Eighty paid undergraduate females from the University of Illinois served as Ss.

Procedure

Two lists of nine letter pairs were taken from Ekstrand \& Underwood (1965), one of high (HA) the other of low (LA) association. Two independent groups of $20 \mathrm{Ss}$ learned each list, one having a retention interval of one day and the other seven days. The four groups designated by letter association level and retention interval are: HA-1, HA-7, LA-1, LA-7.

Each group learned its list to a criterion of seven out of nine items correct by the study test method. The study test procedure consisted of alternate learning and test trials until criterion was met. Each pair or stimulus item was presented singly at a 2 sec rate on all trials. After meeting criterion, the Ss filled in a self paced questionnaire, during which only the stimulus items were presented and the Ss had to indicate the response and the method used to learn each pair. At the completion of the questionnaire the $S$ was given a test trial to assess the final level of learning.

At the recall session the $\mathrm{Ss}$ were again administered a questionnaire, using the same procedure as before, and on its completion they were given five successive test trials.

Results

The mean error scores for each group during acquisition (errors to criterion), final acquisition test (following the questionnaire), and the first and fifth recall tests following the retention interval are shown in Table 1. Significantly more errors were

Table 1. Mean numbers of errors made during acquisition, on the final acquisition test and on the recall tests.

\begin{tabular}{lcccc} 
& \multicolumn{2}{c}{ ACQUISITION } & \multicolumn{2}{c}{ RECALL } \\
Group & To Criterion & Final Test & Test 1 & Test 5 \\
LA-1 & 14.75 & 2.75 & 3.20 & 1.25 \\
LA-7 & 19.54 & 3.12 & 4.80 & 3.00 \\
HA-1 & 6.50 & 1.55 & 1.90 & .75 \\
HA-7 & 6.30 & 1.35 & 2.40 & 1.35 \\
\hline
\end{tabular}


Table 2. Proportion of errors during acquisition and on the final test trial in the acquisition session for each learning method.

\begin{tabular}{|c|c|c|c|c|c|c|}
\hline \multirow[t]{2}{*}{ Group } & \multicolumn{2}{|c|}{ NLM } & \multicolumn{2}{|c|}{ Rote } & \multicolumn{2}{|c|}{ Forgotten } \\
\hline & Acquisition & Test & Acquisition & Test & Acquisition & n Test \\
\hline \multicolumn{7}{|l|}{ LA } \\
\hline (means) & 1.47 & .25 & 2.38 & .39 & 3.28 & .88 \\
\hline (totals) & $(302 / 206)$ & $(51 / 206)$ & $(285 / 120)$ & $(47 / 120)$ & $(105 / 32)$ & $(28 / 32)$ \\
\hline \multicolumn{7}{|l|}{ HA } \\
\hline (means) & .57 & .10 & .97 & .18 & 1.22 & .78 \\
\hline (totals) & $(136 / 240)$ & $(25 / 240)$ & $(86 / 89)$ & $(16 / 89)$ & $(28 / 23)$ & $(18 / 23)$ \\
\hline
\end{tabular}

made by Ss learning the LA list during criterion attainment $(p<.01)$, on the final acquisition test ( $p$ $<.01)$, and on both recall tests $(p<.01$ and $p<.05$ for recall Tests 1 and 5). However, the increase in errors from final acquisition test to the first recall test was about the same for both lists, although more of an increase occurred over the seven day retention interval $(p<.01)$.

In Table 2 the proportions of errors as a function of reported learning method are shown. The use of NLMs yields a lower error rate in acquisition ( $p$ $<.01)$. Table 3 shows the proportions of items correctly recalled in terms of whether S's report on the recall questionnaire was the same or different from the report given on the questionnaire in acquisition. In agreement with the results reported by Montague et al (1966), high recall is associated with the correct recall of the NLM used in acquisition $(p<.01)$. Learning by rote yielded better recall than does the forgetting of the NLM used in learning. Discussion

These results confirm those of Ekstrand \& Underwood (1965) in that the HA list was learned more quickly, but that forgetting of both the HA and LA

Table 3. Proportion of items correct on the first recall test categorized in terms of whether the learning method reported at recall was the same as or different from that reported at acquisition.

\begin{tabular}{|c|c|c|c|c|c|c|}
\hline \multirow[t]{2}{*}{ Group } & \multicolumn{2}{|c|}{$\underline{\text { NLM }}$} & \multicolumn{2}{|l|}{ Rote } & \multicolumn{2}{|c|}{ Forgotten } \\
\hline & Same & Different & Same 1 & Different & Same & Different \\
\hline \multicolumn{7}{|l|}{ LA-1 } \\
\hline (mean) & .80 & .33 & .63 & .25 & 0 & 0 \\
\hline (totals) & $(78 / 97)$ & $(1 / 3)$ & $(38 / 60)$ & $(3 / 12)$ & $(0 / 5)$ & $(0 / 4)$ \\
\hline \multicolumn{7}{|l|}{ LA-7 } \\
\hline (means) & .67 & .38 & .53 & .29 & 0 & .03 \\
\hline (totals) & $(57 / 86)$ & $(6 / 16)$ & $(16 / 30)$ & $(2 / 7)$ & $(0 / 9)$ & $(1 / 32)$ \\
\hline \multicolumn{7}{|l|}{ HA-1 } \\
\hline (means) & .93 & .57 & .85 & .42 & 0 & 0 \\
\hline (totals) & $(103 / 11$ & 1) $(4 / 7)$ & $(34 / 40)$ & $(5 / 12)$ & $(0 / 7)$ & $(0 / 3)$ \\
\hline \multicolumn{7}{|l|}{ HA-7 } \\
\hline (means) & .88 & .50 & .69 & 0 & 0 & .07 \\
\hline (totals) & $(101 / 115$ & 5) $(2 / 4)$ & $(29 / 42)$ & $(0 / 1)$ & $(0 / 1)$ & $(1 / 14)$ \\
\hline
\end{tabular}

items was the same. However, the verbal reports throw some light on the question of why this experiment, along with others, failed to confirm the extraexperimental interference hypothesis. Both HA and LA items, when learned with NLMs which were remembered at recall, were themselves well recalled. One might argue from this finding that the main determinant of retention is not whether or not the letters are highly associated with one another, but whether an NLM can be formed between them. Our results do suggest that it is easier to form NLMs for HA than for LA pairs, since the errors to criterion were greater for LA. However, once an NLM is formed, letter association becomes a relatively unimportant variable.

\section{References}

ADAMS, J. A. Human memory. New York: McGraw-Hill, 1967. EKSTRAND, B. R., \& UNDERWOOD, B. J. Free learning and recall as a function of unit-sequence and letter-sequence interference. J. verbal Learn. verbal Behav., 1965, 4, 390-396.

KIESS, H. O., \& MONTAGUE, W. E. Natural language mediators in paired-associate learning. Psychon. Sci, 1965, 3, 549-550.

MONTAGUE, W. E., ADAMS, J. A., \& KIESS, H. O. Forgetting and natural language mediation. J. exp. Psychol, 1966, 72, 829833.

MONTAGUE, W. E., \& WEARING, A. J. The complexity of natural language mediators and its relation to paired-associate learning. Psychon. Sci., 1967, 7, 135-136.

POSTMAN, L. The present status of interference theory. In C. N. Cofer (Ed.), Verbal learn. \& verbal behav. New York: McGra;r-Hill, 1961.

POSTMAN, L. The effect of language habits on the acquisition and retention of verbal associations. J. exp. PsychoL, 1962, 64, 7-19. UNDERWOOD, B. J. Interference and forgetting. Psychol Rev., 1957, 64, 49-60.

UNDERWOOD, B. J., \& EKSTRAND, B. R. An analysis of some shortcomings in the interference theory of forgetting. Psychol. Rev., 1966, 73, 540-549.

UNDERWOOD, B. J., \& EKSTRAND, B. R. Word frequency and accumulative proactive inhibition. J. exp. Psychol., 1967, 74, 193198.

UNDERWOOD, B. J., \& KEPPEL, G. Retention as a function of degree of learning and letter-sequence interference. Psychol. Monogr., 1963, 77, No. 4 (Whole No. 567).

UNDERWOOD, B. J., \& POSTMAN, L. Extra-experimental sources of interference in forgetting. Psychol Rev., 1960, 67, 73-95.

UNDERWOOD, B. J., \& SCHULTZ, R. W. Meaningfulness and verbal learning. Chigaco: Lippincott, 1960.

WEARING, A. J., \& MONTAGUE, W. E. Associability of CVC-word pairs and its relationship to list difficulty. Psychon. Sci., 1967, 7, 133-134.

\section{Notes}

1. This research was supported in part by the Joint Services Electronics Program (U. S. Army, U. S. Navy, and U. S. Air Force) under Contract No. DA 28043 AMC 00073 (E), and in part by Contract OEC-3-6-058375-0612.

2. The authors are grateful to Clinton Walker, Rosemary Wearing and Douglas Atwood for their assistance in carrying out this research. 